\title{
MIDAS
}

Museus e estudos interdisciplinares

$8 \mid 2017$

Dossier temático "Objetos e museus: biografias, narrativas e vínculos identitários"

\section{A presença na ausência: a performance e a biografia dos objetos como ativadores de memória}

Diego Lemos Ribeiro, Mara Rosana Araujo Alessandretti, Ramile da Silva Leandro, Larissa Tavares Martins e Fabiane Rodrigues Moraes

\section{OpenEdition}

Journals

Edição electrónica

URL: http://journals.openedition.org/midas/1286

DOI: $10.4000 /$ midas. 1286

ISSN: 2182-9543

Editora:

Alice Semedo, Paulo Simões Rodrigues, Pedro Casaleiro, Raquel Henriques da Silva, Ana Carvalho

Refêrencia eletrónica

Diego Lemos Ribeiro, Mara Rosana Araujo Alessandretti, Ramile da Silva Leandro, Larissa Tavares Martins e Fabiane Rodrigues Moraes, « A presença na ausência: a performance e a biografia dos objetos como ativadores de memória », MIDAS [Online], 8 | 2017, posto online no dia 31 julho 2017, consultado no dia 30 abril 2019. URL : http://journals.openedition.org/midas/1286 ; D01 : 10.4000/ midas. 1286

Este documento foi criado de forma automática no dia 30 Abril 2019.

\section{(c) (i) (2)}

Midas is licensed under a Creative Commons Attribution-NonCommercial-ShareAlike 3.0 International License 


\title{
A presença na ausência: a performance e a biografia dos objetos como ativadores de memória
}

\author{
Diego Lemos Ribeiro, Mara Rosana Araujo Alessandretti, Ramile da Silva \\ Leandro, Larissa Tavares Martins e Fabiane Rodrigues Moraes
}

\section{NOTA DO EDITOR}

Artigo recebido a 09.03.2017

Aprovado para publicação a 24.07.2017

\section{Introdução}

1 O presente artigo $^{1}$ centra-se em três estudos de caso a partir de objetos dotados de valores tangíveis e intangíveis, em espaços-tempo diversos, portadores de peculiaridades similares nas suas biografias: a presença na ausência. Para além disso, propõe-se neste estudo uma abordagem da performance e da biografia dos objetos como meio de ativar a "vida" destes patrimónios. O conceito de vida tratado no artigo é diametralmente oposto à ideia postulada de espaços, pelo menos no senso comum, associados com a morte, o congelamento e a taxidermização cultural. Por outras palavras, a vida é neste contexto compreendida como a memória em ação, que insere o bem cultural numa rede de interlocução com pessoas, tempos e outros artefatos; é, portanto, a memória ativada socialmente. A morte, em oposição, redunda na amnésia social, no vazio de sentidos. Assim, sublinham-se três pontos que se consideram relevantes para o debate: a deterioração como prenúncio da morte, a invisibilidade na materialidade e a ausência como elementos mediadores de memória coletiva. 
2 A motivação para esta análise tem como ponto de partida o papel assumido pelos objetos na teoria social contemporânea, mais especificamente nos cenários patrimoniais. Ressalta-se que a escolha dos diferentes casos foi intencional para que se perceba que objetos díspares na sua natureza constitutiva podem ser vistos pelo mesmo prisma, ou seja, através da performance e da biografia entendidas como formas de ativar o espírito dos artefatos, impedindo a força do esquecimento. O conceito de espírito do lugar é utilizado na Declaração de Québec (2008), onde o termo se relaciona com instâncias tangíveis e intangíveis, com o intuito de «proteger e promover o espírito dos lugares, isto é, sua essência de vida, social e espiritual» (ICOMOS 2008, s/p).

O artigo esboça-se, doravante, tendo como referência os três estudos de caso que, em seguida, se consideram. Os casos selecionados para reflexão estão relacionados com as vivências dos autores, sendo a matéria fruto de questionamentos e considerações nas suas interações com esses objetos. No caso do vestido do Museu Municipal Parque da Baronesa (Pelotas, Rio Grande do Sul, Brasil), um dos autores trabalha quotidianamente no museu referido, acompanhando de perto a deterioração do acervo. A experiência com o painel da Igreja Matriz de Santa Vitória do Palmar (Rio Grande do Sul) justifica-se por estar situado no município residente de um dos autores. Em relação à fonte histórica criada por Horst Hoheisel em Kassel (Alemanha), um dos autores realizou um estágio com o artista e a sua equipa durante a Documenta (13), em 2012.

o primeiro caso aborda questões relacionadas com o fim iminente do corpo material e a tentativa de recuperação da sua alma (ver Gonçalves, Guimarães e Bitar 2013), daquilo que não é visível aos olhos, mas que lhe dará e ainda lhe dá forças e poder para permanecer onde está: um vestido musealizado, desgastado pelo tempo, mas "costurado" de memórias.

caso não se tecem considerações sobre a iminência do fim, mas sim sobre as consequências sociais e identitárias que a remoção e a sua destruição podem causar. Trata-se de uma pintura sacra que foi propositadamente eliminada, em 2005, do altar da Igreja Matriz de Santa Vitória do Palmar.

6 No terceiro caso analisa-se o "lugar de amnésia", ou seja, os «lugares onde somente o esquecimento trabalhou, dado que a lembrança era muito pesada para ser carregada» (Candau 2014, 157). Neste contexto aborda-se uma fonte histórica, idealizada em 1908, em Kassel.

7 No caso do vestido pertencente ao acervo do Museu Municipal Parque da Baronesa e da pintura do altar da Igreja Matriz de Santa Vitória do Palmar, recorreu-se à análise de documentos históricos relacionados com os estudos de caso, à pesquisa bibliográfica e, posteriormente, à interação com as comunidades envolvidas, através de entrevistas. Já no caso da fonte histórica de Kassel, o estudo realizou-se, primeiramente, na comunicação e trabalho in loco com o artista Horst Hoheisel, complementado com uma revisão de literatura sobre o tema, e posterior reflexão com os demais autores. Através desta lente teórico-metodológica, calibraram-se olhares para os objetos em questão, que, independentemente da sua natureza material ou espectral (as ausências), podem ter as suas memórias ativadas e biografadas.

8 A partir desta abordagem procuramos abrir caminhos que superem a leitura epidérmica dos objetos e vislumbrar as materialidades - para aquilo que lhes está ausente, mas, que em justaposição com os "restos" da materialidade, os constituem como património. Pretendemos também explicitar como a performance e a biografia elevam o espírito dos 
ausentes e ganham corpo na memória individual e coletiva na qual se encontram inseridos. Delineia-se uma forma de pensar e agir sobre os patrimónios que extrapole os artifícios convencionais do trato patrimonial, geralmente associados aos expedientes jurídicos da patrimonialização. Além disso, refletir sobre uma forma de ativar o sentido social dos patrimónios - não pela via oficial ou burocrática, mas através da emotividade.

\section{A performance e a biografia: meios para contrariar a amnésia social}

9 Analisaremos a performance com base na biografia de cada estudo de caso, atentando-se na importância da comunicação e da extroversão museológica, e em outros lugares como, por exemplo, a igreja e o espaço público. Como sublinha Schechner (2006):

Performances marcam identidades, dobram o tempo, remodulam e adornam o corpo, e contam estórias. Performances - de arte, rituais, ou da vida cotidiana - são "comportamentos restaurados", "comportamentos duas vezes experienciados", ações realizadas para as quais as pessoas treinam e ensaiam. (Schechner 2006, 2)

Por conseguinte, a performance destaca-se como uma forma de interlocução, a qual tem por intuito ativar no bem patrimonial o que lhe é extrínseco, ou seja, o que está além da sua materialidade. Sendo que os atributos extrínsecos estão, de acordo com Yassuda, «relacionados à contextualização do objeto no tempo e no espaço, sua biografia» (Yassuda 2009, 42). Nesse entremeio, objetivando trazer o ausente para o presente, a ativação patrimonial ganha força, pois além de valorizar o material, serve como evocador do espírito dos objetos, projetando e criando nexos entre espaços-tempo até então desconectados. «É, portanto, essa contração do tesouro da transmissão, como performance de si para um "outro", que permite se falar em reconhecimento. 0 reconhecimento é aqui entendido como uma condição que torna a comunicação possível» (Soares 2013, 164). Além disso, tem como propósito dinamizar as coisas, ou seja, animar prover vida àquilo que por algum motivo está morto, dar essência àquilo que não tem alma.

O olhar atualizado que se propõe sobre os objetos no contexto das políticas patrimoniais tem como propulsor a ideia de biografia dos objetos. O conceito de biografia, sistematizado de forma pioneira por Kopytoff (2008), abre espaço para se pensar numa questão fundamental no campo do património: os objetos devem ser interpretados em ação, mimetizados nos contextos sociais e temporais em que circulam:
Ao fazer a biografia de uma coisa, far-se-iam perguntas similares às que se fazem às pessoas: Quais são, sociologicamente, as possibilidades biográficas inerentes a esse "status", e à época e à cultura, e como se concretizam essas possibilidades? De onde vem a coisa, e quem a fabricou? Qual foi a sua carreira até aqui, e qual é a carreira que as pessoas consideram ideal para esse tipo de coisa? Quais são as "idades" ou fases da "vida" reconhecidas de uma coisa, e quais são os mercados culturais para elas? Como mudam os usos da coisa conforme ela fica mais velha, e o que lhe acontece quando a sua utilidade chega ao fim? (Kopytoff 2008, 92)

12 A perspetiva biográfica dos bens patrimoniais, e dos seus movimentos, dentro e fora das fronteiras institucionais - ou, melhor dizendo, dos seus ciclos de vida - dão sentido à ideia de que os objetos são valorizados na sua interação social. Esta perspetiva coloca-nos, de forma contundente, frente a uma questão nevrálgica dentro do campo epistemológico dos museus: o valor dos objetos não é monolítico ou exatamente objetivo; pelo contrário, o 
valor potencial dos patrimónios só ganha contorno, peso e forma fora dos limites objetivos da sua materialidade.

Importa sublinhar que a conjuntura biográfica, pelo menos na conceção deste estudo, não se abstém do universo material que sustenta o espírito dos objetos. Ao revés, compreende-se que os processos de patrimonialização devem tecer juntos, sempre que possível, materialidades e imaterialidades, corpo e alma, até porque:

É preciso também não esquecer que, enquanto portadora de uma alma, de um espírito, as coisas não existem isoladamente, como se fossem entidades autônomas; elas existem efetivamente como parte de uma vasta e complexa rede de relações sociais e cósmicas, nas quais desempenham funções mediadoras fundamentais entre a natureza e cultura, deuses e seres humanos, mortos e vivos, passado e presente, cosmos e sociedade, corpo e alma, etc. Essa possibilidade nunca desapareceu completamente de nosso horizonte moderno. (Gonçalves, Guimarães e Bitar 2013, 8)

Atendendo à fundamentação anteriormente referida, defende-se que a finitude das materialidades, em termos utilitários e da sua manifestação física, não determina a morte do bem patrimonial, ou seja, a morte não se consubstancia com o fim da matéria, mas, sobretudo através da amnésia social.

\section{0 corpo em fase terminal e a tentativa de recuperação da sua alma}

Principiamos pelos trajes transformados em "trapos e trecos" - mais especificamente o vestido em análise - a biografia revelada demonstra uma peça muito além de uma simples indumentária. Conforme discorre Loureiro $(2015,10)$, «[...] os objetos constituem uma parte significativa da prática cultural humana», acumulando-se nas residências e, de algum modo, sendo detentores de poder. Por outro lado, Pearce sublinha: «os objetos são importantes para as pessoas porque lhes atribuem prestígio e posição social; em termos sociais, a maioria dos objetos pertencentes às nossas coleções de vestuário, belas artes $\mathrm{e}$ artes aplicadas sobreviveu por esta razão» (Pearce 2005, 19).

O Museu Municipal Parque da Baronesa é um museu de hábitos e costumes do final do século XIX e início do século XX, dotado de uma expografia rica em móveis, utensílios, têxteis e documentos, que visa contar como vivia uma parte da população na cidade de Pelotas. A 25 de abril de 2017, o museu completou 35 anos. 0 vestido em questão (fig. 1) encontra-se cedido a esta instituição na forma de empréstimo e, como objeto em exposição, indica na sua tabela apenas a referência a quem pertenceu. Tal acervo tem por objetivo representar os saraus tradicionalmente oferecidos pela sociedade pelotense no século XIX, tornando-se assim um cenário pertinente no discurso museográfico. No entanto, cabe salientar que o vestido, após anos de uso, está desgastado pelo tempo e pela excessiva exposição à luz e à intempérie. 


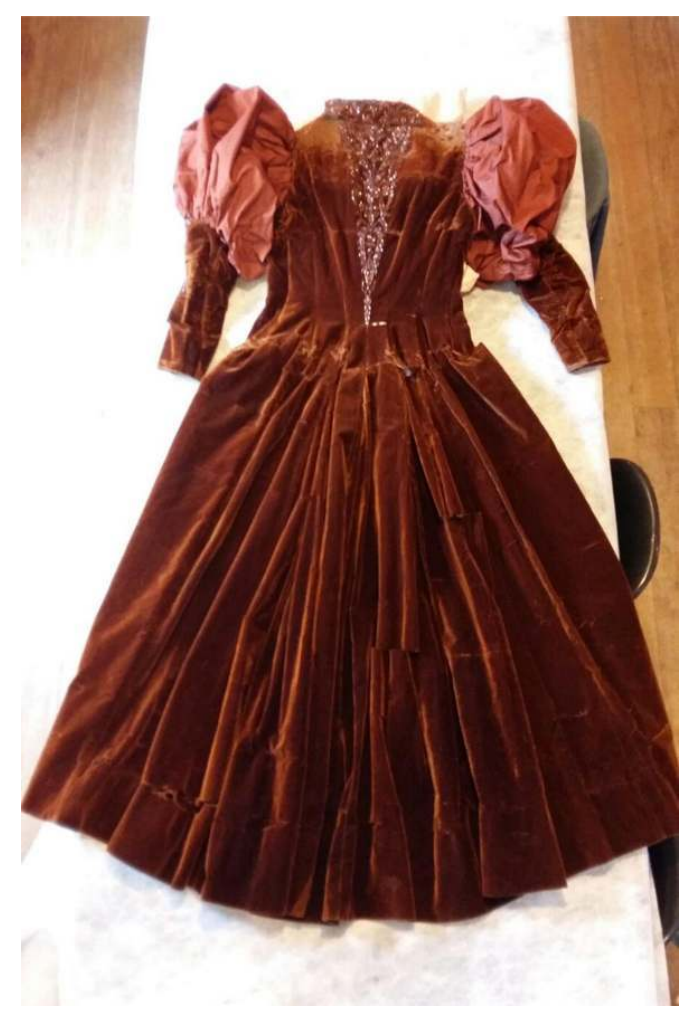

Fig. 1 - Vestido na reserva técnica, 2016, Museu Municipal Parque da Baronesa Fotografia de Marcelo Madail

\section{O risco iminente do fim}

O sinal de alerta já existia, mas agora a emergência realmente aconteceu - o que fazer com esse vestido? Guardar em reserva e manter os seus "restos" sob os cuidados da equipe da conservação é a primeira e, aparentemente, a única opção encontrada pelo museu. Deitado sobre uma mesa, o vestido castanho de mangas bufantes repousa prostrado no mais nobre cemitério: o museu. No discurso de Valéry:

Diante de mim se desenvolve, no silêncio, uma estranha desordem organizada. Sou tomado de um horror sagrado. Meu passo torna-se piedoso. Minha voz muda e se faz um pouco mais alta que na Igreja, mas soa um pouco menos forte que na vida comum. (Valéry 2008, 32)

Na sua morte simbólica permite-se pensar sobre a sua vida, pois será afinal possível associar tudo o que já foi mencionado ao vestido que repousa sobre a sua "provável" última morada? Perante os factos, torna-se imprescindível colocar três questões baseadas na sua biografia: de quem foi este vestido? Qual foi a sua trajetória? o que conta a partir do momento que se desconecta do espaço expositivo? Ao ocupar um lugar nobre no museu, já se lhe confere outro signo: o advento da alma impregnado de memória. Neste contexto, encerrado no anonimato por 26 anos e já desgastado pelo tempo, aproxima-se a iminência do fim de mais um ciclo de vida, destino que certamente será compartilhado com os demais objetos. Face a este fim provável, o que fazer com este legado? Pelo menos em termos conceituais, um dos caminhos seria criar meios de evocar os "espíritos" que habitavam o vestido. $O$ ritual de evocação é aqui caracterizado como a biografia que pode dar alento aos objetos condenados à morte material. 
19 No que diz respeito aos trajes de época, uma das formas de comunicar estes acervos é a performance com aspeto teatral, em que a representação é o ponto principal a ser abordado, sendo a experiência sensível uma forma de trazer à vida objetos que estão em risco de morte. A representação é uma das formas de conectar o invisível ao visível, ou seja, serve para projetar e conectar espaços e tempos até então desconectados, unindo vivos e mortos, ausência e presença. Para esta conceção refira-se a ideia de semióforo desenvolvida por Pomian. Para este autor, semióforos são «objetos que não têm utilidade, no sentido que acaba de ser precisado, mas que representam o invisível, são dotados de um significado; não sendo manipulados, mas expostos ao olhar, não sofrem usura» (Pomian 1984, 71). E explica:

O semióforo desvela o seu significado quando se expõe ao olhar. Tiram-se duas conclusões: a primeira é que um semióforo acede à plenitude do seu ser semióforo quando se torna uma peça de celebração; a segunda, mais importante, é que a utilidade e o significado são reciprocamente exclusivos: quanto mais carga de significado tem um objeto, menos utilidade tem, e vice-versa. (Pomian 1984, 72)

As encenações têm o objetivo de provocar o olhar para coisas que já não existem, procurando interpretar a história vivida. Soares (2012) declara que os «museus não podem ser concebidos como templos ou fóruns, palácios ou cemitérios, porque é muito mais útil pensá-los como palcos» (Soares 2012, 203). Esta encenação, quando protagonizada por objetos que compõem o cenário patrimonial, é inserida numa teia de semântica e de significados que, de alguma forma, causa impacto de âmbito cognitivo.

\section{No altar: o nascimento da obra}

No caso da pintura de altar da Igreja Matriz de Santa Vitória do Palmar observa-se outra fase de vida do objeto. Na igreja, o corpo - o altar - está presente, mas cria-se uma falsa história no momento em que se tenta apagar os vestígios de um tempo passado. $O$ caráter sagrado que se transformou no painel deve-se à intencionalidade do artista ao local onde está inserido e às redes de crenças e significados que lhe são socialmente atribuídos. Pomian sublinha que o caráter sagrado refere-se a «todos os objetos que servem ao culto religioso» (Pomian 1984, 83-84), não sendo, portanto, uma simples pintura: nesse sentido, a obra possuiria «significados mágico-religiosos» (Gonçalves 2005, 18). É no sentido defendido por Gonçalves, uma obra que se revela como entidade dotada de espírito, não se tratando, assim, de um mero objeto.

Em meados do século XIX, logo após a formação da Povoação de Andrea² ${ }^{2}$ em Santa Vitória do Palmar, foi construída a primeira capela da localidade. Rodrigues $(2010,59)$ relata que o ato partiu do Coronel Manoel Corrêa Mirapalhete, fundador do município, que contratou um pedreiro com o intuito de construir uma humilde capelinha de madeira, coberta de palha, para oficializar os rituais religiosos daquele povoado. No decorrer dos anos a obra foi passando por transformações graduais incluindo-se, nesse trajeto, a pintura no altar da Igreja relacionada. 0 trabalho artístico (fig. 2) foi doado à igreja pelo artista João Carlos Petruzzi ${ }^{3}$ na década de 1960. Na apreciação de Rodrigues (2010) este foi «[...] o seu maior e mais significativo trabalho que saiu de sua inspiração e do motivo religioso [...]» (Rodrigues 2010, 59). A partir daí a pintura passou a ser um elemento da composição do lugar. Presume-se que a obra, através do tempo, tenha adquirido significados e valores, tornando-se um dos símbolos da comunidade. No âmbito do valor conferido ao objeto, Pomian considera que o mesmo provém dos benefícios que este 
apresenta, pois «para que um valor possa ser atribuído a um objeto por um grupo ou por um indivíduo, é necessário e suficiente que esse objeto seja útil ou que seja carregado de significado» (Pomian 1984, 72). Sendo assim, a relação objeto/sociedade permeia pelo valor e significado através do seu reconhecimento e utilidade, com história e memória abarcando relações físicas, culturais e sociais envoltas num só objeto, neste caso o altar da igreja matriz.

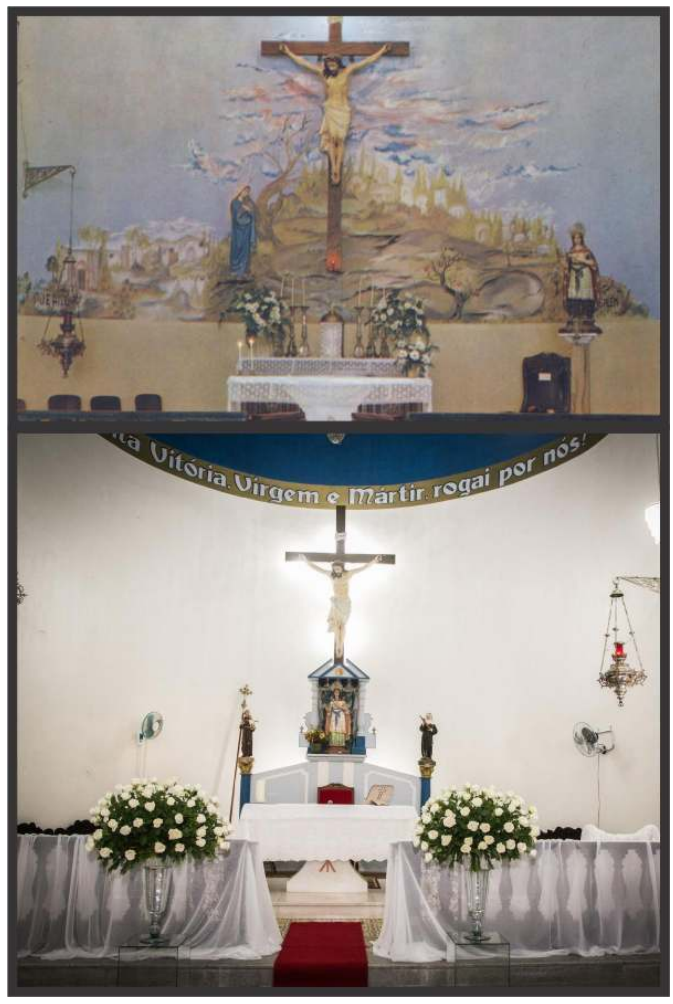

Fig. 2 - Altar antes e depois da remoção da pintura sacra. Igreja Matriz de Santa Vitória do Palmar, 2017

Fotografia de Sergio Olivera Gonzalez. Arquivo Foto e Vídeo Color

\section{O súbito fim da pintura mural}

Em dezembro de 2005 - exatamente na data em que se comemorava o sesquicentenário do município -, baniu-se repentinamente a pintura dos registos e celebrações sacramentais. Por decisão do pároco à época, a pintura foi removida. Segundo testemunho de Rodrigues (s/d), a pintura foi eliminada por «uma mão irresponsável, desrespeitando a tradição e a vontade de muitos que se orgulhavam de seu trabalho, colocou por terra um momento tão rico de expressão deste vulto conterrâneo» (Rodrigues s/d, s/p).

Esta situação gerou conflitos na comunidade. $O$ objeto permaneceu durante 40 anos no altar-mor da Igreja sendo, frequentemente, apontado como elemento significativo para a comunidade, seja como valorização da obra de um conterrâneo, ou como plano de fundo nas fotografias de casamentos, batizados e outras festividades da comunidade católica. As inúmeras contestações contra a eliminação da pintura tornaram-se evidentes quando um grupo de senhoras devotas decidiu protestar. O seu recado de desaprovação foi transmitido na missa campal alusiva aos 150 anos do município. As manifestantes anunciaram-se através de um abaixo assinado e da criação de um painel ${ }^{4}$ (fig. 3) que 
refletia traços semelhantes aos produzidos pelo pintor conterrâneo, juntamente com uma faixa com os dizeres «Queremos de volta o que nos foi tirado».

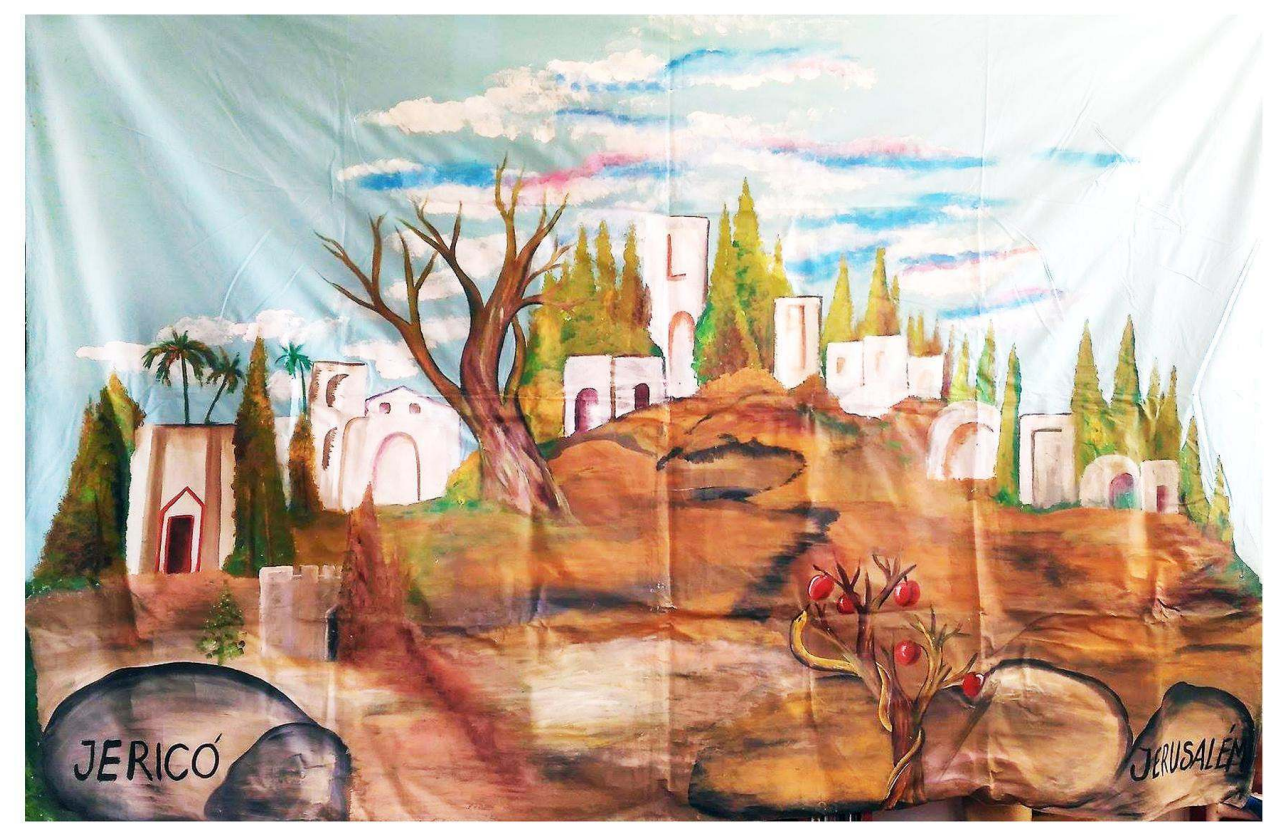

Fig. 3 - Painel criado para retratar a pintura do altar, em 2005

Fotografia de Sergio Olivera Gonzalez. Arquivo Foto e Vídeo Color, 2017

As manifestações tinham o intuito de comunicar o que fora lamentavelmente perdido, ações que, no entender de Pomian, permitem «falar dos mortos como se estivessem vivos, dos acontecimentos passados como se fossem presentes, do longínquo como se fosse próximo, e do escondido como se fosse manifesto» (Pomian 1984, 68). As declarações apontaram como culpado pelo sucedido o sacerdote local. Tal facto pode ser comprovado em artigo no jornal $O$ Vitoriense: «Arte essa a esplender na nave da nossa igreja, símbolo perene da nossa fundação. Um inconsequente e obscuro surrealismo, profanou as sagradas imagens santificadas da nossa original capela, patrimônio histórico de Santa Vitória» (Azambuja 2005, 6). Estas narrativas remetem novamente para o que Pomian descreve, reforçando a responsabilidade daqueles que ocupam posições que implicam funções de salvaguarda de objetos comuns de uma sociedade. Conforme refere Pomian, «num mundo onde o invisível se apresenta não tanto sob os traços da eternidade quanto sob os do futuro, a proteção das artes é um dever de qualquer príncipe que queira aceder a uma verdadeira glória [...]» (Pomian 1984, 78).

\section{Reminiscências de um corpo sem alma}

Atualmente a pintura desaparecida do altar-mor é apenas representada através de fotografias e pelo painel elaborado, reafirmando a sua existência perante o seu desaparecimento, com um discurso para a história, já que «os objetos materiais têm uma trajetória, uma biografia» (Meneses 1998, 92). Do material restam apenas lembranças sentimentais, marcadas pelos momentos sagrados, oriundos da relação litigiosa entre comunidade e igreja.

Nora refere que a memória não é semelhante aos detalhes que a sustentam, pois alimentase de lembranças vagas ou projeções, «da mesma forma que o futuro visível, previsível, 
manipulável, balisado ${ }^{5}$ projeção do presente, tornou-se invisível, imprevisível, incontrolável [...]» (Nora 1993, 19). A presença do painel reproduzido comporta-se como um "despertar da memória", provocando um ritual de encarnação, com a missão de retomar a alma da pintura, reconstruindo a história. Permanece a questão: e o que está encoberto no recôndito do corpo poderá servir de resgate para captar a ausência da alma?

Destacando-se como imagem para contemplação e ensinamento, a pintura mural da Igreja - possuía uma grande potência de evocação -, mas após ter entrado num recinto sagrado passa, «com efeito, para um campo rigorosamente oposto ao das atividades utilitárias [...] por isso os objetos têm aí apenas uma função: ser expostos ao olhar [...]» (Pomian 1984, 57). Após a sua eliminação, a pintura foi ocultada da vista dos seus fiéis, «uma vez oferecidos aos deuses, em teoria, os objetos deveriam ficar para sempre no templo que os tinha acolhido» (Pomian 1984, 57). Outros sim têm a missão de conservar a memória do seu feitor, como se alguém no futuro continuasse a recuperar parte de uma vivência. Para Soares (2013):

O objeto de culto se artifica tanto por suscitar uma emoção estética (ligada à emoção religiosa), quanto por ser estudado como objeto de arte. Nesse sentido, tal processo não significa a mera passagem de não-arte a arte, mas trata-se de uma reconfiguração dos dispositivos e das justificações mobilizados em torno desses objetos de arte católica que, então, passam a funcionar, eles mesmos, como atores na performance museal. (Soares 2013, 160)

Sendo a instância material que se destaca como elemento promotor de performance, para a pintura da igreja será a musealização ${ }^{6}$ e a elaboração da biografia do painel reproduzido, que animará o corpo e dará sentido às suas particularidades históricas, por ora ausentes. Soares (2014) destaca que "ao eleger artefatos que serão destituídos de sua função original, ao 'roubar-lhes a alma dando-lhes uma outra', a musealização, altera a realidade das coisas transformando presenças em significados» (Soares 2014, xxxiii). É na realização do painel, que acompanha o grupo em datas demarcadas, que se observa a necessidade da guarda de uma "lembrança" de algo que fez parte de uma época nos seus ritos sacramentais.

\section{Quando o objeto sai de cena para enaltecer o ausente e dar corpo ao imaginário: a biografia da Fonte Aschrott (1908-1939; 1987)}

30 No terceiro estudo de caso analisamos a Fonte Aschrott e a ausência do corpo - anulação proposital da materialidade sobre o solo - que provoca a ativação do espírito do lugar. É o vazio intencional que, justamente, é utilizado para despertar a história, a materialidade da fonte e a sua biografia.

31 Em 1908, Sigmund Aschrott, empresário influente da cidade Kassel, instruiu o arquiteto Karl Roth para projetar uma fonte para o novo edifício da câmara municipal. A fonte foi construída em forma de obelisco sobre uma bacia histórica de arenito no pátio da câmara municipal. Em pouco tempo tornou-se uma característica e ponto de referência da cidade e, uma vez que se encontrava numa zona de grande prestígio, era considerada como símbolo de orgulho cívico, e consequentemente, de identidade dos cidadãos de Kassel. No dia 9 de abril de 1939, os ativistas nacional-socialistas de Kassel, num ato aprovado pelo governo local, destruíram este património. A fonte, antes associada ao orgulho 
cívico, transformou-se num símbolo do seu ódio: o seu fundador, Sigmund Aschrott, era judeu. E durante os anos de pós-guerra, as autoridades da cidade aprovaram a remoção dos "restos" da fonte. No entanto, em meados dos anos 1960, o ato simbólico de levar flores para a base da mesma fez com que se transformasse numa grande floreira, quase um túmulo de memórias e factos enterrados. $\mathrm{O}$ artista Horst Hoheisel, que teve a sua infância marcada por estes factos, relata que durante a sua infância «a fonte se tornara um símbolo de memórias reprimidas, do desejo de esquecer» ${ }^{7}$ (Hoheisel 1985, s/p).

O silêncio instaurado em relação ao objeto perturbou muitas pessoas que na ocasião da oitava edição do festival de arte contemporânea - Documenta (8) ${ }^{8}$, em 1986, conseguiram a aprovação do lançamento do edital para a reconstrução da obra. 0 projeto do artista Horst Hoheisel foi selecionado para despertar as memórias adormecidas do monumento. ${ }^{9}$ O projeto previa a construção de uma réplica da Fonte Aschrott tal como foi construída em 1908. Contudo, o projeto distinguia-se quando ao local de instalação da réplica: na mesma base da antiga fonte, mas de forma negativa, abaixo do solo.

\section{Da amnésia à memória do ausente: a nova fonte de Horst Hoheisel}

A 10 de dezembro de 1987 foi inaugurada a nova Fonte de Aschrott ${ }^{10}$, representando nas palavras do artista: «uma escultura pública que é o presente em virtude da ausência» ${ }^{11}$ (Hoheisel 2012, 432). A aprovação do projeto causou grande impacto, provocando numerosos debates públicos na cidade. Mesmo durante a sua construção, a fonte continuou a evocar grande interesse entre os moradores de Kassel. Segundo relatos do artista, «esse interesse continua muito vivo até hoje, intrigando especialmente os jovens, curiosos para saber mais sobre o período mais sombrio da história da sua cidade, agora resgatado do esquecimento, pois é um memorial no sentido mais profundo da palavra, um estimulante para a memória» ${ }^{12}$ (Hoheisel 1985, s/p).

Desta forma, a fonte não somente renasceu, como também ganhou força simbólica transformando-se em «antimonumento, uma escultura pública que é presente em virtude de sua ausência» ${ }^{13}$ (Hoheisel 2012, 432). Força essa que, na ausência da materialidade cresce e se dissemina, uma vez que «por definição, o invisível é o que não se pode atingir, que não se pode dominar com os meios que normalmente se utilizam na esfera do visível» (Pomian 1984, 69) aniquilando qualquer ameaça de nova destruição material, dando às memórias corpo e alma.

Assim, analisando este caso pelo viés da arte, pode dizer-se que a performance se encontra viva na interação/negação entre público e obra. Isto porque o artista criou uma fonte que só apresenta sentido quando uma reação com esta ocorre, ou seja, quando provoca/acorda os fantasmas da memória. Para Canclini, a expansão da arte fora do seu campo é a responsável pela criação de uma «zona de interseção entre artistas e espectadores» (Canclini 2012, 220). Neste contexto, pode elaborar-se o questionamento cerne desta investigação como sendo: a ausência pode servir de pilar para o suporte da memória? Esta ausência projeta o espectador para um lugar que é muito presente, trazendo memórias, nas quais o vácuo, o espaço e a abstração são um impulso para trazer à tona os significados desse património, através da performance artística. Conforme defende Schechner (2004):

A performance se origina da necessidade de fazer que as coisas aconteçam e entretenham; obter resultados e brincar; mostrar o modo como são as coisas e passar o tempo; transformar-se em um outro e ter prazer em ser você mesmo; 
desaparecer e se mostrar; incorporar um outro transcendente e ser "apenas eu" aqui e agora; estar em transe e no controle; focar no próprio grupo e transmitir ao maior número de pessoas possível; jogar para satisfazer uma necessidade pessoal, social ou religiosa; e jogar somente com contrato ou por dinheiro! (Schechner 2004 cit. por Ligiéro 2012, 83)

Para Dohmann e Fernandes (2013) «objetos ou coisas sempre remetem para lembranças de pessoas ou lugares, quer seja uma simples fotografia, ou um marco arquitetural» (Dohmann e Fernandes 2013, 33). Esta conjuntura opõe-se ao conceito de Pomian (1984) que salienta que é o visível que projeta para o invisível: No caso da fonte, acontece ao contrário, pois é o invisível que projeta para aspetos visíveis, onde a ausência material é um estímulo para a ativação patrimonial.

\section{Considerações finais}

Ao examinar os três ciclos de vida referentes aos objetos apresentados: o vestido em fase terminal, destacando-se como um corpo fadado à morte; o altar da Igreja sem a pintura sacra, apresenta-se como um corpo desfalecido, despido da sua alma; e a fonte, da qual a materialidade foi propositalmente anulada, exprime a extinção do seu corpo e também da sua alma. E, apesar das particularidades dos objetos, inclusive em termos geográficos, e da sua natureza constitutiva, a performance e a biografia podem ser utilizadas como dispositivos para ativar o "espírito" destes patrimónios, estejam estes manifestos ou ausentes em termos materiais.

Exaltar a ativação do imaterial constituiu o objetivo primordial deste artigo, salientando que qualquer objeto ganha força quando se consegue estimular o que é extrínseco. É através da dinâmica cultural que se pretende ampliar as ações performáticas para fora do espaço restrito do museu, despertando espíritos antes adormecidos. Na tentativa de reavivar o espírito do lugar, intensificaram-se os elementos que deram vida e performance às coisas.

Por tudo o que se referiu são apresentadas respostas para os questionamentos iniciais, reconhecendo que as performances teatral, museal e artística, juntamente com a biografia, têm a capacidade de dar um fim digno ao vestido, à pintura e à fonte; de mostrar os seus destroços, expor as suas marcas e contar as suas histórias. Têm a capacidade de atuar como veia propulsora para que a ausência se possa tornar um pilar para o suporte da memória; de dar um corpo ao vestido, buscando a sua trajetória, e assim, manter a sua vida patrimonial - mesmo na ausência - através da teatralidade. Do mesmo modo, são capazes de desvendar o que está encoberto no recôndito do corpo - no altar - através do registo de narrativas e da musealização do painel reproduzido. Para além disso, servirão de mediadores para captar a ausência da alma da fonte, através das ativações alojadas nas interpretações artísticas.

Para finalizar, destaca-se que cada ciclo de vida tem um término e, mesmo após a morte, ainda há oportunidade de se evocar o espírito. Pois, em se tratando de bens patrimoniais e de toda a "sacralidade" que possuem, a questão entre vivo/morto, passado/presente e material/espiritual apresenta-se muito ténue. Desta forma, a análise dos três casos e a investigação sobre a performance e a biografia, que se lhes aplicou, é importante para desmantelar o prenúncio existente e ativar, de algum modo, o património que se encontra suspenso no tempo. Além do mais, ressalta-se que a iminente ameaça de perda do corpo e 
da alma devem ser evitadas, tendo em conta que as formas de ativação patrimonial são importantes para prolongar a vida material e espiritual dos acervos.

Defende-se a procura de um equilíbrio entre salvaguardar, pesquisar e comunicar, ampliando a qualidade da informação oferecida aos visitantes. A performance e a biografia têm a função de complementar essas outras áreas de estudo e comunicação, bem como atuar na conquista de alargar as visitas a lugares de memória como museus, templos e construções esculturais.

\section{BIBLIOGRAFIA}

Azambuja, Péricles. 2005. "Da Santa Vitória Imperial aos Nossos Dias.” O Vitoriense, dezembro 24, p. 6.

Canclini, Néstor Garcia. 2012. A Sociedade sem Relato: Antropologia e Estética da Iminência. Tradução de Maria Paula Gurgel Ribeiro. São Paulo: Editora da Universidade de São Paulo.

Candau, Joël. 2012. Memória e Identidade. Tradução de Maria Letícia Ferreira. São Paulo: Contexto.

Dohmann, Marcus, e Amaury Fernandes. 2013. A Experiência Material: A Cultura do Objeto. Rio de Janeiro, Rio Books.

Gonçalves, José Reginaldo Santos, Roberta Sampaio Guimarães, Nina Pinheiro Bitar, orgs. 2013. A Alma das Coisas: Patrimônios, Materialidades e Ressonâncias. Rio de Janeiro: Mauad X: Faperj (Fundação Carlos Chagas Filho de Amparo à Pesquisa do Estado do Rio de Janeiro.

Gonçalves, José Reginaldo Santos. 2005. "Ressonância, Materialidade e Subjetividade: As Culturas como Patrimônios.” Horizontes Antropológicos 11 (23): 15-36. Porto Alegre

Hoheisel, Horst. 1985. “Aschrott Fountain [Kassel 1985].” Consultado em março 5, 2017. http:// www.knitz.net/index.php?option=com_content\&task=view\&id=30\&Itemid=143

Hoheisel, Horst. 2012. “Aschorott Fountain.” In Das Begleitbuch/The Guidebook Documenta (13), 432-433. Kassel: Hatje Cantz.

ICOMOS. 2008. Declaração de Québec. Québec: ICOMOS (Conselho Internacional de Monumentos e Sítios. https://www.icomos.org/images/DOCUMENTS/Charters/

GA16_Quebec_Declaration_Final_PT.pdf

Kopytoff, Igor. 2008. “A Biografia Cultural das Coisas: A Mercantilização como Processo.” In A Vida Social das Coisas, ed. Arjun Appadurai, 89-121. Niterói: Editora da Universidade Federal Fluminense.

Ligiéro, Zeca. 2012. Performance e Antropologia de Richard Schechner. Rio de Janeiro: Mauad X. Loureiro, Maria Lucia de Niemeyer Matheus. 2015. "Musealização e Cultura Material da Ciência \& Tecnologia." Museologia e Patrimônio. Revista Eletrônica do Programa de Pós-Graduação em Museologia e Patrimônio 8 ( 2): 9-28.

Meneses, Ulpiano T. Bezerra de. 1998. "Memória e Cultura Material: Documentos Pessoais no Espaço Público.” Estudos Históricos 11 (21): 89-103. 
Nora, Pierre. 1993. “Entre Memória e História: A Problemática dos Lugares.” Projeto História 10 (dezembro): 7-28.

Pearce, Susan M. 2005. “Pensando sobre os Objetos.” In MAST Colloquia (Museu: Instituição de Pesquisa) 7: 11-22.

Pomian, Krystof. 1984. “Coleção.” In Enciclopédia Eunaudi, v. 1, 51-86. Lisboa: Imprensa Nacional da Moeda.

Rodrigues, Homero Suaya Vasques. (s/d). "João Carlos Leonetti Petruzzi - Um dos Maiores Artistas da Terra. Um Conterrâneo de Múltiplas Atividades Culturais." Consultado em dezembro 16, 2016. http://www.planetsul.com.br/htm/colunistas/colaboradores/homero/ anteriores/280620101.htm

Rodrigues, Homero Suaya Vasques. 2010. Recado aos Mergulhões: Evolução da História dos Campos Neutrais Santa Vitória do Palmar e Chuí. Santa Vitória do Palmar: Gráfica Lin, Poligraf.

Schechner, Richard. 2006. “O que é Performance?" In Performance Studies: An Introduction, 2nd ed., 28-51. New York: Routledge.

Soares, Bruno César Brulon. 2012. "Entre o Reflexo e a Reflexão: Por Detrás das Cortinas da Performance Museal.” In Encontro Regional ICOFOM LAM, 1ed. Rio de Janeiro: Universidade Federal do Estado do Rio de Janeiro/Museu de Astronomia e Ciências Afins, orgs. Tereza C. Scheiner, Marcus Granato, Maria Amélia de Souza, e Gladys Barrios Ambrocy, 192-204. [s.l.]: MAST (Museu de Astronomia e Ciências Afins).

Soares, Bruno César Brulon. 2013. "Da Ratificação do Sagrado nos Museus: Entre o Teatro e a Sacralidade." In Anais do Museu Paulista: História e Cultural Material 21 (2): 155-175.

Soares, Bruno César Brulon. 2014. “As Coleções de Museus Criam Conexões: Percursos da Musealização no Musée du Quai Branly.” Anais da VI Semana Nacional de Museus na UNIFAL, MG 6: xxii-xxxvi.

Valéry, Paul. 2008. “O Problema dos Museus.” ARS (São Paulo) 6 (12): 31-34.

Yassuda, Sílvia Nathaly. 2009. "Documentação Museológica: Uma Reflexão sobre o Tratamento Descritivo do Objeto no Museu Paulista.” Dissertação de mestrado em Ciência da Informação, Universidade Estadual Paulista (UNESP).

\section{NOTAS}

1. $O$ artigo surgiu das discussões realizadas na disciplina Acervos Documentais e Preservação do Património Histórico do programa de pós-graduação em Memória Social e Patrimônio Cultural da Universidade Federal de Pelotas, Rio Grande do Sul, no Brasil.

2. Povoação de Andrea - nome dado ao primeiro povoado que se formou na localidade por volta de 1855.

3. João Carlos Petruzzi, nascido em Santa Vitória do Palmar, era formado em artes plásticas e dedicou parte da sua vida à docência, a peças teatrais e à pintura.

4. O painel criado não só foi utilizado durante as manifestações de protesto, como também é visto em algumas festividades noutra igreja católica da mesma localidade.

5. Mantém-se a ortografia conforme a escrita da obra.

6. Por musealização compreendemos a ativação memorial do objeto numa dinâmica cultural complexa, por meio da recolha, salvaguarda e comunicação das suas memórias. Não implica, neste sentido, inseri-lo em vitrines ou imobilizá-lo institucionalmente. 
7. Tradução dos autores.

8. A cada cinco anos em Kassel (Alemanha), desde 1951, artistas de todo mundo encontram-se no festival de arte contemporânea intitulado Documenta, que prima por discutir temas políticosociais mundiais.

9. Imagens do desenho e execução do projeto de Horst Hoheisel, 1985 - 1987 podem ser visualizadas no website do artista: http://www.knitz.net/index.php? option=com_content\&task=view\&id=30\&Itemid=143 (consultado em dezembro 16, 2016).

10. Imagens da Fonte Aschrott (1986-87) de Horst Hoheisel e a maquete do projeto podem ser visualizadas no website do artista: http://www.knitz.net/index.php? option=com_content\&task=view\&id=30\&Itemid=143 (consultado em dezembro 16, 2016).

11. Tradução dos autores.

12. Tradução dos autores.

13. Tradução dos autores.

\section{RESUMOS}

Este estudo aborda a consolidação do património com base no ciclo de vida de legados culturais evocados no seu final de vida. Trata-se, neste contexto, do desgaste, do desaparecimento e da destruição de três artefactos que entrelaçam em si as ideias de pertença, história e memória, a partir das quais se procura examinar as dualidades que encerram as ideias de vida/morte, corpo/ alma e materialidade/imaterialidade. Os estudos de caso focam um vestido (museu), uma pintura sacra de um altar (igreja) e uma fonte (espaço público). As razões para esta escolha prendem-se com a intenção de realçar diferentes situações que envolvem uma abordagem patrimonial a bens culturais, trabalhadas a partir de um prisma singular: a performance dos objetos associada à biografia cultural. A biografia é neste âmbito compreendida como a vida em potência e a performance como a sua ativação memorial, que, na aceção adotada neste texto, seria a trajetória de fuga da amnésia social.

The presence in the absence: the performance and objects biography as memory activators This paper addresses the consolidation of heritage based on the life cycle of cultural legacies evoked at the end of their life. In this context deals with the wear and tear, disappearance and destruction of three artefacts that interweave ideas of belonging, history and memory, from which one seeks to examine the dualities that enclose the ideas of life/death, body/soul and materiality/immateriality. The case studies dealt are a dress (museum), a sacred painting of an altar (church) and a fountain (public space). The reasons for this choice - of seemingly disparate artefacts - are related to the aim of highlighting different situations involved in the heritage approach to cultural assets, working from a singular prism: the performance of objects associated with cultural biography. Biography is therefore understood as life in potency and performance as memorial activation, which, in the sense adopted in this paper, would be the escape route of social amnesia. 


\section{ÍNDICE}

Keywords: heritage, memory, object biography, performance, Horst Hoheisel

Palavras-chave: património, memória, biografia de objeto, performance, Horst Hoheisel, Museu Municipal Parque da Baronesa, Igreja Matriz de Santa Vitória do Palmar

\section{AUTORES}

\section{DIEGO LEMOS RIBEIRO}

Doutor em Arqueologia pela Universidade de São Paulo (Brasil), mestre em Ciência da Informação pela Universidade Federal Fluminense e graduado em Museologia pela Universidade Federal do Estado do Rio de Janeiro. É professor da Universidade Federal de Pelotas desde 2008 e docente efetivo do programa de pós-graduação em Memória Social e Patrimônio Cultural. Tem experiência na área da Museologia, nomeadamente em ciência da informação e arqueologia. Atualmente desenvolve trabalhos e orienta pesquisas na área da gestão e da comunicação em museus, nomeadamente de acervos arqueológicos e etnográficos.

Programa de pós-graduação Memória Social e Patrimônio Cultural da Universidade Federal de Pelotas, Campus II - R. Almirante Barroso, 1202, Centro, 96010-280 Pelotas, Rio Grande do Sul, Brasil, dlrmuseologo@yahoo.com.br

\section{MARA ROSANA ARAUJO ALESSANDRETTI}

Bacharel em Turismo pela Universidade Federal do Rio Grande (Brasil). Tem desenvolvido atividades na área da educação patrimonial, do património cultural, da memória e da identidade. Tem interesse na área do património cultural, da memória e da preservação.

Programa de pós-graduação Memória Social e Patrimônio Cultural da Universidade Federal de Pelotas, Campus II - R. Almirante Barroso, 1202, Centro, 96010-280 Pelotas, Rio Grande do Sul, Brasil, amararosana@yahoo.com.br

\section{RAMILE DA SILVA LEANDRO}

Mestre em Progettazione e Cura Degli Allestimenti Artistici pela Accademia di Belle Arti di Firenze (2013). Especialista em História da Arte (2010) pelo Instituto Michelangelo - ambas as pós-graduações em Florença, Itália; licenciada em Artes Visuais pela Universidade Federal do Rio Grande (2009). Atualmente desenvolve projetos culturais e investigação na área da arte contemporânea, arquivo, memória e património, e mercado de arte.

Programa de pós-graduação Memória Social e Patrimônio Cultural da Universidade Federal de Pelotas, Campus II - R. Almirante Barroso, 1202, Centro, 96010-280 Pelotas, Rio Grande do Sul, Brasil, ramileleandro@hotmail.com

\section{LARISSA TAVARES MARTINS}

Mestre em Património Cultural (2015) pela Universidade Federal de Santa Maria (Brasil) e licenciada em Artes Visuais (2011). É especialista em Artes, na linha de Patrimônio Cultural Conservação de Artefatos - Universidade Federal de Pelotas (2013). Desenvolve investigação na área do património, cultura material, conservação, comunicação, acervos têxteis e artes. 
Programa de pós-graduação Memória Social e Patrimônio Cultural da Universidade Federal de Pelotas, Campus II - R. Almirante Barroso, 1202, Centro, 96010-280 Pelotas, Rio Grande do Sul, Brasil, larissamartins.ufpel@gmail.com

\section{FABIANE RODRIGUES MORAES}

Mestranda como bolseira do programa de pós-graduação em Memória Social e Patrimônio Cultural do Instituto de Ciências Humanas da Universidade Federal de Pelotas (Brasil). Tem bacharelado em Conservação e Restauro de Bens Culturais Móveis, pela Universidade Federal de Pelotas. Desenvolve investigação na área das instituições de memória e da gestão de acervos. Programa de pós-graduação Memória Social e Patrimônio Cultural da Universidade Federal de Pelotas, Campus II - R. Almirante Barroso, 1202, Centro, 96010-280 Pelotas, Rio Grande do Sul, Brasil, rmconservacaoerestauro@gmail.com 